\title{
Maternity and Mental Health during COVID-19 Pandemic: Empirical Reflections from North India
}

\section{Mohammed Arafat Hasan Rizvi}

Research Scholar, Centre for Women's Studies, Aligarh Muslim University, Aligarh, India E-Mail: arafat.hasanrizvi@gmail.com

\section{Dr. Faisal Hassan}

Assistant Professor, Department of Psychology, Mohammad Ali Jauhar University, Rampur, India E-Mail: faisal.hassan.rizvi@gmail.com

\section{Abstract}

Post-Partum Depression (PPD) has been a psychological as well as social concern for the working women and has been an area of contemporary behavioural research. It has given rise to various other issues which differ on physical, psychological and social terms. Numerous studies have addressed the factors that result into Post-Partum depression. Review of recent relevant literature suggests that the Post-Partum depression is comparatively more among working women as compared to the non-working women. During the outbreak of COVID-19, the working class had to adapt to the new normal of working from home. Likewise, the working women too had to resort to homes which impacted their work schedules and posed new challenges before them. Working and Non-working women who experienced pregnancy during these times were recruited for the research study. Past studies have consistently shown a negative correlation between Post-Partum Depression and Social Support during pregnancy. Considering the importance of the variables in these extraordinary times, the research study aimed at exploring the dynamics of variables when measured among the groups of working women and home maker women. The study investigated Marital Adjustment and Social Support with respect to Post-Partum Depression. Results were obtained through a dedicated framework of statistical tests and the final interpretations hint towards several significant relationships between the variables.

Keywords: Post-Partum Depression, Marital Adjustment and Social Support, Maternity, Mental Health, COVID-19

\section{Prologue}

Motherhood and parenting are extremely emotional experience for women and they often transform the personality of women those who undergo them. Motherhood has been considered as a traditionally significant event across societies and cultures. Conception, pregnancy and delivery of a child is an event which is generally considered as an occasion that is on one hand pleasurable 
and instills happiness bringing joy to a family, while on the other hand there are other facets of it which are often not very pleasurable and often go unnoticed. Women often don't divulge their emotional distress due to fear of being judged, negativity, shame and guilt; consequently they start accumulating and enduring stress that often leads them into trauma. It has been observed that new mothers often get reluctant about the psychological conditions in which they find themselves after the delivery of child and end up getting affected by Post-Partum Depression (PPD).

During the outbreak of COVID-19 Pandemic, most of the working class resorted to their homes for containment of the spread of virus. As India struggles with the second wave and a probable third wave is lurking, the duration of COVID-19 Pandemic has affected human life greatly. It is imperative to understand how 'working from home' has impacted people in general and women in particular, and also among women who delivered their child during these unprecedented times.

This study entails an investigation into the facets of maternity characterized by Post-Partum Depression and perspectives of mental health represented by Marital Adjustment and Social Support. This study is an attempt to examine the prevalence of Post-Partum Depression among working \& non-working women during the outbreak of COVID-19 Pandemic in Lucknow, Uttar Pradesh. Furthermore, the study is aimed at exploring \& understanding the dynamics of marital adjustment \& social support which are presumed to be having considerable effects on the symptoms of Post-Partum depression. It is believed that there is no single cause for Post-Partum depression, therefore physical, emotional, social, and personal factors may all play a role but mostly it has been noticed that in the developing countries the situation occurs mostly due to financial instability, as a result people experience social or marital problems. 


\section{Background of the study}

Women in India, particularly in the northern regions have reportedly been experiencing depression, major depressive disorder, sweating, palpitations, nausea, faintness, an overwhelming urge to run away, sadness, hopelessness, low self-esteem, guilt, a feeling of being overwhelmed, sleep and eating disturbances, inability to be comforted, exhaustion, emptiness, anhedonia, social withdrawal, low or no energy, become easily frustrated, feeling inadequate in taking care of the baby, impaired speech and writing, spells of anger towards others etc., following their deliveries. In the capital city of Uttar Pradesh, Lucknow, it has been observed that females who have such symptoms usually lack social support, marital adjustment problems \& depends upon the status of women, i.e. either they are working women or non-working, such symptoms result in Post-Partum Depression (PPD). The current study sought to develop understanding of whether the problem of PPD is related to working \& housekeeping women, social support or marital adjustment during the ongoing COVID-19 Pandemic.

\section{Post-Partum Depression}

Post-Partum Depression (PPD) has been noted as one of the leading causes of maternal morbidity, emerging as a public health concern. It could be understood as a major depressive episode which is associated with child birth. It is generally characterized by a persistently depressed mood which lasts more than two weeks (Miller, 1996). Post-Partum Depression (PPD) could be diagnosed as far as up to a year after the child has been delivered by the mother (Beck, 2001). 


\section{Social Support}

Social Support is understood as an intended action that is given willingly to a person with whom there is a personal relationship, and that produces embarks an immediate or sometimes a delayed positive response in the person at whom it is targeted (Logsdon \& Usui, 2001). Social could be understood as the groups of people within a community, society or neighborhoods that share common goals, interests and values. The perception of social support is often seen as an evaluation by women following the significance of a particular type of support and how much of that support is received at the end. It could be said that social support is a key element that facilitates and hinders the development and shaping of personality during specific conditions in which individuals are presented with challenges.

\section{Marital Adjustment}

Marital adjustment could be defined for as a lack of spousal proximity and support, or being in a conflictive or abusive relationship. It has implications for both adults as well as their children. Generally, depressed women report more marital maladjustment than non-depressed women, which is illustrated by poor communication, sentimental friction, disengagement, and often sexual problems (Kung, 2000). Marital dysfunctions could persist for long durations after the woman clinically recovers from the depression (Stein et al., 1991). Furthermore, it has been observed that the quality of the primary intimate relationship and the presence of depressive symptoms have predicted future parenting attitudes (Hall et al., 1991). 


\section{Objectives of the study}

The objectives of the present study were as under:

1. To examine the levels of Post-Partum depression among the working wives during COVID-19 Pandemic.

2. To examine the levels of Post-Partum depression among the non-working wives during COVID-19 Pandemic.

3. To identify the relationship between Post-Partum depression and social support among working wives during COVID-19 Pandemic.

4. To find out the relationship the relationship between Post-Partum depression and social support among non-working wives during COVID-19 Pandemic.

5. To examine the relationship between Post-Partum depression and marital adjustment among working wives during COVID-19 Pandemic.

6. To identify the relationship between Post-Partum depression and marital adjustment among non-working wives during COVID-19 Pandemic.

\section{Hypotheses}

H1. There is a statistically significant relationship between Post-Partum depression and Marital Adjustment.

H2. There is a statistically significant relationship between Post-Partum depression and Socialsupport. 
H3. There is a statistically significant relationship between Social-Support and Marital Adjustment.

H4. The Post-Partum depression will be high among non-working wives as compared to working wives.

H5. The Post-Partum depression among non-working wives depends upon the marital adjustment and social support.

H6. There is a statistically significant relationship between Post-Partum depression and Marital Adjustment among non-working wives.

H7. There is a statistically significant relationship between Post-Partum depression and Socialsupport among non-working wives.

H8. There is a statistically significant relationship between Social-Support and Marital Adjustment among non-working wives.

H9. The level of Post-Partum depression among working wives depends upon the marital adjustment and social support.

H10. There is a statistically significant relationship between Post-Partum depression and Marital Adjustment among working wives.

H11. There is a statistically significant relationship between Post-Partum depression and Socialsupport among working wives.

H12. There is a statistically significant relationship between Social-Support and Marital Adjustment among working wives. 


\section{Methodology}

The purpose of this research study is to examine the post-partum depression among working and non-working wives and its subsequent relationship with marital adjustment and social support during the outbreak of COVID-19 Pandemic and analyze the impact of the extraordinary situations that have prevailed. Therefore quantitative approach would be considered in order to establish the causal and existing relationships between the variables of the study.

\section{Research Design}

The study enshrines a comparative and correlational research design in order to extract and examine the dynamics of maternal health and related factors. The research has implied convenience sampling which is a non-probability sampling technique. Since quantitative approaches enable study of diverse populations and involve comparison between the measures, the study has made use of it.

\section{Sample}

The sample comprised of 200 women that included 100 working wives and 100 nonworking wives, from different walks of life, all of them were based in Lucknow, the capital city of Uttar Pradesh during the course of research. The women were in the age range of 20 to 40 years and have had a delivery within 3-6 months of the current study. All the respondents were provided with the informed consent form and only those who displayed the intent of participation, were included in the research from different areas of the city of Lucknow.

The educational qualifications ranged from Matriculation to Masters and M.Phil/PhD level. Most of the postgraduate women were among the working women's group. The current research 
implied a non-random sampling technique and specifically the accidental sampling technique was used, where by any respondent who was part of the population and happened to be within reach of the researcher was included in the study.

\section{Inclusion and Exclusion Criteria}

Exclusively those women were included in the study who had delivered their babies 4-6 weeks ago and were showing signs Post-Partum depression. All those women who showed no signs of Post-Partum depression were excluded from the research study.

\section{Tools}

\section{Beck Depression Inventory (BDI)}

The Beck Depression Inventory (BDI) is an important instrument for the measurement of depression and its severity. It is a 21 item scale that assesses the intensity and magnitude of depression among individuals. Every item comprises of a list of four statements arranged in an ascending order with regards to symptoms of depression. This version of the BDI complies with DSM-IV criteria for assessment of depression, and covers the individuals from the age range of 13 to 80 years. Cronbach's alpha is .92 for clinical patients and .93 for non-clinical individuals and test-retest reliability is .93 , while it has concurrent validity. Items on the BDI-II are rated on a 4point scale ranging from zero to three. Some items have seven response options to discern differences in behavior or motivation. The BDI-II is scored by adding the ratings for the 21 items. The maximum total score is 63 . 


\section{Multidimensional Scale of Perceived Social Support (MSPSS)}

The Multidimensional Scale of Perceived Social Support (MSPSS) devised by Zimet et al. (1988) measures perception of social support. It is designed to measure the subjective assessment of individual's social support adequacy from three specific sources: family, friends and significant others. It is an instrument consisting of 12-items in a Likert format scale. The MSPSS is scored by summing individual item scores for the total and subscale scores and dividing by the number of items; the theoretical range of total scores is 12-84. Higher scores on the MSPSS reflect higher perception of social support. The reliability of the scale is .88 and indicates good internal consistency and the MSPSS has strong factorial validity and moderate construct validity (Zimet et al., 1988).

\section{Locke-Wallace Marital Adjustment Test (LWMAT)}

The Locke-Wallace Marital Adjustment Test (LWMAT) devised by Locke \& Wallace (1959) was administered to test marital adjustment. It has been designed to measure the accommodation of partners to each other at any given time, spouses. It assesses happiness with the spouse and the effectiveness of marriage, degree of agreement on marital issues such as affection, philosophy of life, etc; level of companionship experienced, and abilities to resolve conflict constructively (Sabatelli, 1988). This scale consists of 15 items in Likert format. The scoring of the scale is done by summing the score on all items, which are weighted differently; the theoretical range of scores is 2 to 158 . The cutting score of less than 100 indicates maladjustment. It was one of the first measures of marital adjustment and can be easily considered, despite its age, one of the most widely used instruments by contemporary researchers (Sabatelli, 1988). The internal 
consistency of the Lock-Wallace is very good, with a correlation of .90. The LWMAT has evidence of known-group validity, with scores discriminating between adjusted and maladjusted couples.

\section{Procedure}

The heads of the department of different maternity hospitals and psychiatric OPDs in Lucknow were contacted regarding the permission to conduct the study. The study was done in an ethical manner that respected the integrity, dignity, right and welfare of the subjects. Informed consent was taken and confidentiality of the particulars was assured to all the recruited participants. Sampling was done through non-random sampling technique and the study incorporated questionnaires. Followed by the data collection, the Statistical Package for Social Sciences (SPSS) software was used to derive the output. Statistical tests such as mean, SD, t-test, variance, correlation and one-way ANOVA were used.

\section{Result \& Discussion}

Following the successful administration of the tools on the participants of the study, raw scores were obtained which were then tabulated for the purpose of the data analysis. Primarily, the participants were asked about their employment statuses as shown in Table 1. Followed by the application of statistical procedures and different data analysis techniques, the results were obtained and subsequently inferences were carved, the particulars of which are displayed in the tables to follow. 
Table 1.1: Employment Status

\begin{tabular}{lcr}
\hline Group & Frequency & Percent \\
\hline Working Women & 100 & 50.0 \\
Non-working Women & 100 & 50.0 \\
\hline Total & 200 & 100.0 \\
\hline
\end{tabular}

As displayed by Table 1.1, there were total 200 respondents; it describes the employment status of the respondent women, further stating that $50 \%$ of the respondents were working women, while the rest $50 \%$ of the participants were non-working women.

Table 1.2: Descriptive Statistics

\begin{tabular}{cccc}
\hline & Mean & SD & N \\
& & & \\
\hline Post-Partum Depression & 28.4850 & 12.27654 & 200 \\
Marital Adjustment & 68.9400 & 29.47593 & 200 \\
Social Support & 40.0900 & 15.48129 & 200 \\
& & & \\
\hline
\end{tabular}

As shown by Table 1.2, the mean for Post-Partum Depression (PPD) came out to be 28.4850, while the Standard Deviation (SD) was 12.27654; similarly the mean for Marital Adjustment (MA) was 68.9400 and the SD was 29.47593; and the mean for Social Support (SS) was 40.0900 while the SD was observed as 15.48129 . 
Table 1.3: Model Summary

\begin{tabular}{ccccc}
\hline Model & R & R Square & $\begin{array}{c}\text { Adjusted R } \\
\text { Square }\end{array}$ & $\begin{array}{c}\text { Std. Error of } \\
\text { the Estimate }\end{array}$ \\
\hline 1 & $.608^{\mathrm{a}}$ & .370 & .363 & 9.79489 \\
\hline
\end{tabular}

a. Predictors: (Constant), Social Support, Marital Adjustment

An observation of table 1.3, it could be inferred that the regression model is a good fit for the observed data, as a higher value of R-squared would mean a better fit for the regression model. The variables reported through the model were Social Support and Marital Adjustment.

Table 1.4: Pearson Product Moment Correlation

\begin{tabular}{llll}
\hline Variables & $\begin{array}{l}\text { Post-Partum } \\
\text { Depression }\end{array}$ & Marital Adjustment & Social Support \\
\hline $\begin{array}{l}\text { Post-Partum } \\
\text { Depression }\end{array}$ & $\mathbf{1}$ & $\mathbf{. 5 6 9 * *}$ & $\mathbf{- . 5 0 7 * *}$ \\
$\begin{array}{l}\text { Marital Adjustment } \\
\text { Social Support }\end{array}$ & $\mathbf{1}$ & $\mathbf{. 5 8 6 * *}$ \\
\hline$* *$ Correlation is significant at the 0.01 level (2-tailed) & $\mathbf{1}$ \\
\hline
\end{tabular}

The Pearson Product Moment Correlation is the measure of strength and direction of the association which presumably existent between the variables. An observation of table 1.4, it could be seen that there is a negative correlation between Post-Partum Depression and Social Support, while a positive correlation exists between Post-Partum Depression and Marital Adjustment. Moreover, there is a positive correlation existing between Marital Adjustment and Social Support. 
Journal of Advance Research in Science and Social Science (JARSSC)

ISSN: 2582-2004

Volume 04, Issue 01

DOI: $10.46523 /$ jarssc. 04.01 .01

Open Access

Table 1.5: ANOVA ${ }^{b}$

\begin{tabular}{ccccccc}
\hline \multicolumn{1}{l}{ Model } & $\begin{array}{c}\text { Sum of } \\
\text { Squares }\end{array}$ & Df & Mean Square & F & Sig. \\
\hline 1 & Regression & 11091.812 & 2 & 5545.906 & 57.806 & $.000^{\text {a }}$ \\
& Residual & 18900.143 & 197 & 95.940 & & \\
& & & & & & \\
& Total & 29991.955 & 199 & & & \\
\hline
\end{tabular}

a. Predictors: (Constant), Social Support, Marital Adjustment

b. Dependent Variable: Post-Partum Depression

Table 1.6: Coefficients ${ }^{\text {a }}$

\begin{tabular}{|c|c|c|c|c|c|c|}
\hline & \multirow[b]{2}{*}{ Model } & \multicolumn{2}{|c|}{$\begin{array}{c}\text { Unstandardized } \\
\text { Coefficients }\end{array}$} & \multirow{2}{*}{$\begin{array}{c}\begin{array}{c}\text { Standardized } \\
\text { Coefficients }\end{array} \\
\text { Beta }\end{array}$} & \multirow[b]{2}{*}{$\mathbf{t}$} & \multirow[b]{2}{*}{ Sig. } \\
\hline & & B & Std. Error & & & \\
\hline \multirow[t]{3}{*}{1} & (Constant) & 48.777 & 2.051 & & 23.779 & .000 \\
\hline & Marital Adjustment & -.173 & .029 & -.415 & -5.946 & .000 \\
\hline & Social Support & -.209 & .055 & -.263 & -3.773 & .000 \\
\hline
\end{tabular}

a. Dependent Variable: Post-Partum Depression

The regression analysis aims to put the emphasis upon investigating the dependence of one or more variable upon one or more variables. In this study, the researchers have studied the dependence of PostPartum Depression on Marital Adjustment and Social Support with respect to COVID-19 Pandemic. The results displayed in the above tables have shown that there is a positive relationship between Marital Adjustment and Post-Partum Depression score, as well as Social Support score and Post-Partum Depression. 
Journal of Advance Research in Science and Social Science (JARSSC)

ISSN: 2582-2004

Volume 04, Issue 01

DOI: $10.46523 /$ jarssc. 04.01 .01

Open Access

The estimated regression model is given as under:

$$
\begin{aligned}
& Y=\text { Post-Partum Depression, } X_{1}=\text { Marital Adjustment and } X_{2}=\text { Social Support } \\
& \qquad Y=48.77+0.173 X_{1}+0.209 X_{2}
\end{aligned}
$$

Therefore, it has been established that $37 \%$ of variation of Post-Partum Depression is being explained by Marital Adjustment \& Social Support.

Table 1.7: Mean difference among working and non-working women on Post-Partum Depression

\begin{tabular}{cccccc}
\hline \multicolumn{5}{c}{ Post-Partum Depression } \\
\hline Groups & N & Mean & s.d. & t-value & $\boldsymbol{p}$-value \\
Working & 100 & 36.5600 & 8.90048 & & \\
Non-Working & 100 & 20.4100 & 9.59176 & 12.342 & .001 \\
& & & & & \\
\hline
\end{tabular}

The t-test shows that there is significant difference between the level of Post-Partum Depression in working women and non-working women, as the p value is less than the predefined level of significance which is alpha $=0.05$. Also, as evident from the group statistics displayed in Table 1.7, that the average score of Post-Partum Depression among non-working women is 36.65 while among the working women has come out as 20.41. Therefore, it could be ascertained that the level of Post-Partum Depression is lower among non-working women as compared to working women. 
Journal of Advance Research in Science and Social Science (JARSSC)

ISSN: 2582-2004

Volume 04, Issue 01

DOI: $10.46523 /$ jarssc. 04.01 .01

Open Access

Table 1.8: Regression Analysis for Non-working Women

Descriptive Statistics ${ }^{a}$

\begin{tabular}{lccc}
\hline & Mean & SD & N \\
\hline Post-Partum depression & 36.5600 & 8.90048 & 100 \\
Marital Adjustment & 43.3400 & 13.08034 & 100 \\
Social Support & 29.7700 & 10.47928 & 100 \\
& & & \\
\hline
\end{tabular}

a. Employment Status $=$ Non-working

Table 1.9: Model Summary ${ }^{b}$

\begin{tabular}{lrrrr}
\hline Model & R & R Square & $\begin{array}{c}\text { Adjusted R } \\
\text { Square }\end{array}$ & $\begin{array}{l}\text { Std. Error of } \\
\text { the Estimate }\end{array}$ \\
\hline 1 & $.107^{\mathrm{a}}$ & .012 & -.009 & 8.93988
\end{tabular}

a. Predictors: (Constant), Social Support, Marital Adjustment

b. Employment Status $=$ Non-working

Table 1.10: Pearson Product Moment Correlation

\begin{tabular}{llll}
\hline Variables & $\begin{array}{l}\text { Post-Partum } \\
\text { Depression }\end{array}$ & Marital Adjustment & Social Support \\
\hline $\begin{array}{l}\text { Post-Partum } \\
\text { Depression }\end{array}$ & 1 & $.105^{* *}$ & .024 \\
Marital Adjustment & 1 & .026 \\
Social Support & & & 1 \\
\hline
\end{tabular}

**Correlation is significant at the 0.01 level (2-tailed) 
Journal of Advance Research in Science and Social Science (JARSSC)

ISSN: 2582-2004

Volume 04, Issue 01

DOI: $10.46523 /$ jarssc. 04.01 .01

Open Access

Table 1.11: ANOVA ${ }^{b, c}$

\begin{tabular}{|c|c|c|c|c|c|c|}
\hline \multicolumn{2}{|c|}{ Model } & \multirow{2}{*}{$\begin{array}{r}\begin{array}{c}\text { Sum of } \\
\text { Squares }\end{array} \\
90.256\end{array}$} & \multirow{2}{*}{ Df } & Mean Square & \multirow{2}{*}{$\begin{array}{l}\text { F } \\
.565\end{array}$} & \multirow[t]{2}{*}{ Sig. } \\
\hline 1 & Regression & & & 45.128 & & \\
\hline & Residual & 7752.384 & 97 & 79.921 & & \\
\hline & Total & 7842.640 & 99 & & & \\
\hline
\end{tabular}

a. Predictors: (Constant), Social Support, Marital Adjustment

b. Employment Status $=$ Non-working

c. Dependent Variable: Post-Partum Depression

Table 1.12:

Coefficients $^{\mathrm{a}, \mathrm{b}}$

\begin{tabular}{|c|c|c|c|c|c|c|}
\hline \multirow{2}{*}{\multicolumn{2}{|c|}{ Model }} & \multicolumn{2}{|c|}{$\begin{array}{l}\text { Unstandardized } \\
\text { Coefficients }\end{array}$} & \multirow{2}{*}{$\begin{array}{c}\begin{array}{c}\text { Standardized } \\
\text { Coefficients }\end{array} \\
\text { Beta }\end{array}$} & \multirow[b]{2}{*}{$\mathbf{t}$} & \multirow[b]{2}{*}{ Sig. } \\
\hline & & B & Std. Error & & & \\
\hline \multirow[t]{3}{*}{1} & (Constant) & 32.929 & 3.978 & & 8.277 & .000 \\
\hline & Marital Adjustment & .071 & .069 & .105 & 1.035 & .303 \\
\hline & Social Support & .018 & .086 & .022 & .215 & .831 \\
\hline
\end{tabular}

a. Employment Status = Non-working

b. Dependent Variable: Post-Partum Depression

a. Dependent Variable: Post-Partum Depression

The correlation analysis among non-working women showed a positive correlation between Post-Partum Depression and Marital Adjustment that is significant at 0.01 level. While there were no other significant correlations reported among the non-working women on the variables. 
Regression analysis technique was administered in order to investigate the dependence of Post-Partum Depression among non-working women on Marital Adjustment and Social Support. The results showed that the dependence of Post-Partum Depression on Marital Adjustment and Social Support score is insignificant as the $\mathrm{p}$ values are greater than alpha $=0.05$.

Hence, there is a positive correlation between Post-Partum Depression \& Marital adjustment among non-working women, which is 0.105 . The value of $r$ between the Post-Partum Depression \& Marital Adjustment is 0.105, which is insignificant at 5\% level of significance, (p> 0.005). The value of $r$ between the Post-Partum Depression \& Social Support is 0.024, which is insignificant at $5 \%$ level of significance, $(\mathrm{P}>0.005)$. The value of $\mathrm{r}$ between the Marital Adjustment \& Social Support is 0.024, which is insignificant at 5\% level of significance, $(\mathrm{P}>$ $0.005)$.

Table 1.13: Regression Analysis for Working Women

\section{Descriptive Statistics}

\begin{tabular}{lccc}
\hline & Mean & SD & N \\
\hline Post-Partum Depression & 20.4100 & 9.59176 & 100 \\
Marital Adjustment & 94.5400 & 15.85504 & 100 \\
Social Support & 50.4100 & 12.52157 & 100 \\
\hline
\end{tabular}

a. Employment Status $=$ Working 
Journal of Advance Research in Science and Social Science (JARSSC)

ISSN: 2582-2004

Volume 04, Issue 01

DOI: $10.46523 /$ jarssc. 04.01 .01

Open Access

Table 1.14: Model Summary ${ }^{b}$

\begin{tabular}{lrrrr}
\hline Model & R & R Square & \multicolumn{1}{c}{$\begin{array}{c}\text { Adjusted R } \\
\text { Square }\end{array}$} & $\begin{array}{l}\text { Std. Error of } \\
\text { the Estimate }\end{array}$ \\
\hline 1 & $.236^{\mathrm{a}}$ & .056 & .036 & 9.41690
\end{tabular}

a. Predictors: (Constant), Social Support, Marital Adjustment

b. Employment Status $=$ Working

Table 1.15: Pearson Product Moment Correlation

\begin{tabular}{llll}
\hline Variables & $\begin{array}{l}\text { Post-Partum } \\
\text { Depression }\end{array}$ & Marital Adjustment & Social Support \\
\hline $\begin{array}{l}\text { Post-Partum } \\
\text { Depression }\end{array}$ & $\mathbf{1}$ & $\mathbf{. 5 6 3}$ & $\mathbf{- . 0 2 3 *}$ \\
Marital Adjustment & $\mathbf{1}$ & $\mathbf{1}$ \\
Social Support & & \\
\hline *Correlation is significant at the 0.05 level (2-tailed) &
\end{tabular}

Table 1.16:

ANOVA $^{\mathrm{b}, \mathrm{c}}$

\begin{tabular}{llrrrrr}
\multicolumn{1}{l}{ Model } & & $\begin{array}{c}\text { Sum of } \\
\text { Squares }\end{array}$ & Df & Mean Square & F & Sig. \\
\hline 1 & Regression & 506.417 & 2 & 253.209 & 2.855 & $.062^{\mathrm{a}}$ \\
& Residual & 8601.773 & 97 & 88.678 & & \\
& & & & & & \\
& Total & 9108.190 & 99 & &
\end{tabular}
a. Predictors: (Constant), Social Support, Marital Adjustment
b. Employment Status $=$ Working
c. Dependent Variable: Post-Partum Depression 
Table 1.17:

COEFFICIENTS ${ }^{a, b}$

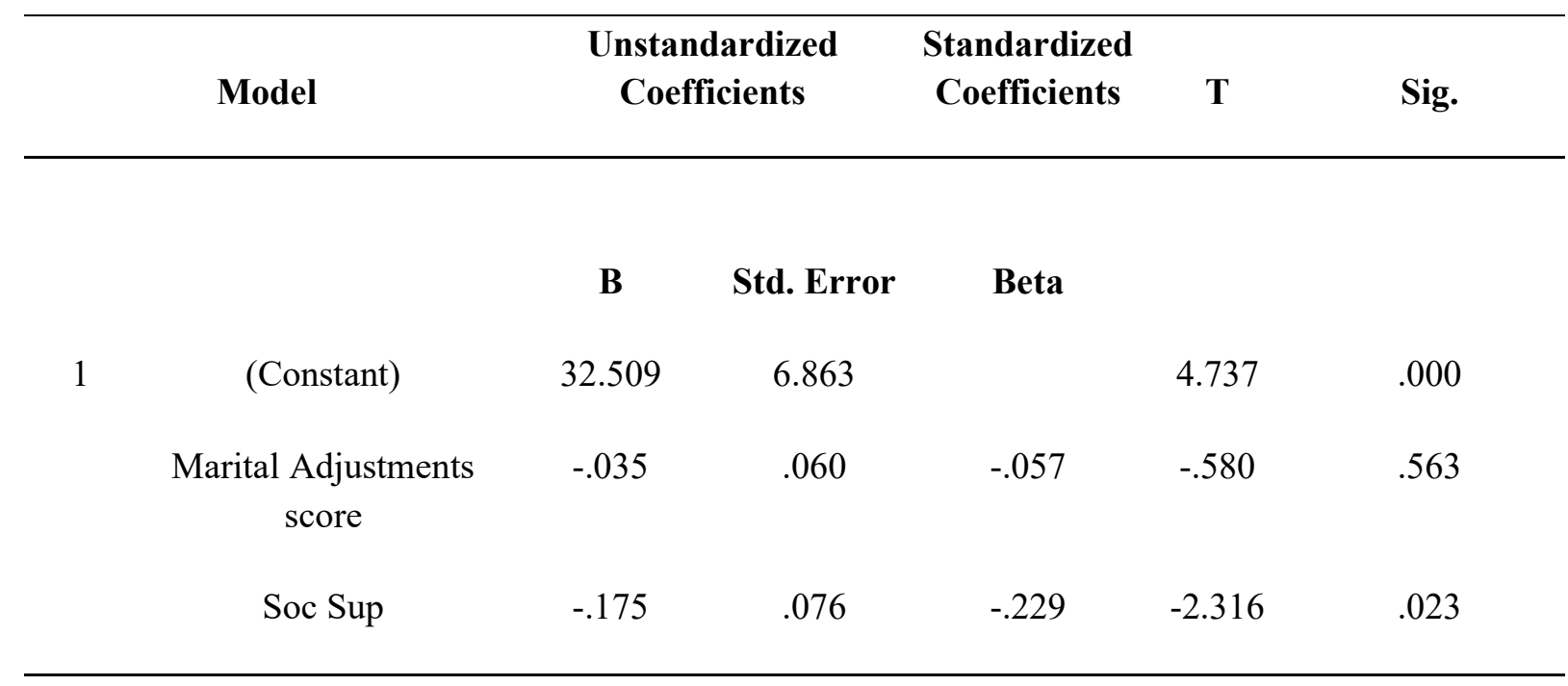

a. Employment Status $=$ Working

b. Dependent Variable: Post-Partum Depression

a. Dependent Variable: Post-Partum Depression

The correlation analysis displayed a negative correlation between Post-Partum Depression and Social Support which was significant at 0.05 level. There were no other correlations observed among the working women on the variables measured and tested.

Regression analysis technique was administered to study the dependence of Post-Partum Depression among the working women, it seems to be significantly dependent upon Social Support as the $\mathrm{p}$ value is 0.23 which is less than alpha $=0.05$, whereas the dependence of Post-Partum Depression among working women insignificantly dependent upon Marital Adjustment as the $\mathrm{p}$ value is 0.563 greater than alpha $=0.05$.

Hence, The Relationship between Post-Partum Depression \& Marital Adjustment among working women is negatively correlated. The value of $r$ between Post-Partum Depression \& 
Marital Adjustment is 0.563 that is insignificant at 5\% level of significance. The Relationship between Post-Partum Depression \& Social Support among working women is negatively correlated. The value of $r$ between Post-Partum Depression \& Social Support is 0.23 that is significant at 5\% level of significance. The value of $r$ between Marital Adjustment \& Social Support is -0.004 that is insignificant at $5 \%$ level of significance.

\section{Conclusion}

It is thus established by the conclusion of this research that the level of Post-Partum Depression is higher among the non-working women as compared to working women, which could be well attributed due to the uncertainties posed by the COVID-19 Pandemic. The Relationship between Post Partum Depression \& Marital Adjustment as well as Social Support among working women is negatively correlated. Whereas, there appears to be a positive correlation between Post Partum Depression \& Marital Adjustment and Social Support among non-working women, which has come out to be 0.105 . There is also a negative relationship between Post-Partum depression \& Marital Adjustment along with the Social Support. Furthermore, there is a strong imminent positive relationship between Marital Adjustment \& Social Support.

Therefore, it could be deduced from the findings of this research study that the extraordinary situations and unforeseen challenges have induced anxiety among people in general and women in particular as they remain at the helm of affairs at home. As the homes have emerged as the new workplaces, the professional challenges have magnified the domestic challenges which have various reasons as their causes. The newly emerged genre of stress due to the lockdowns, containment in homes and uncertainty of future have affected every member of the family dealing directly or indirectly with the COVID-19 Pandemic. Working women have shown some resilience due to the fact that their professions have managed to keep them connected to the outside world. The non-working women, generally housekeeping and home- 
making, in wake of the absence of support from family as well as spouse, have been greatly affected by the Post Partum Depression during the unprecedented times of COVID-19 Pandemic.

\section{References}

Beck, C.T, (2001). Predictors of postpartum depression: an update. Nursing Research, 50:275- 85.

Hall, L., Gurley, D., Sachs, B., \& Kryscio, R. (1991). Psychosocial predictors of maternal depressive symptoms, parenting attitudes and child behavior in single-parenting families. Nursing Research, 40(4):214-219.

Kung, W., (2000). The intertwined relationship between depression and marital distress: Elements of marital therapy conducive to effective treatment outcome. Journal of Marital and Family Therapy, 26:51-63

Locke, H. J., \& Wallace, K. M. (1959). Short marital adjustment and prediction tests:Their reliability and validity. Marriage and Family Living, 21, 251-255.

Logsdon, M. \& Usui, W. (2001). Psychosocial predictors of postpartum depression in diverse groups of women. Western Journal of Nursing Research 23(6), 563-574.

Miller, L. (1996). Major mental illness during pregnancy. Primary Care Update Ob/ Gyns. 6, 163-168.

Sabatelli, R.M. (1988). Exploring Relationship Satisfaction: A Social Exchange Perspective on the Interdependence between Theory, Research and Practice. Family Relations, 37(2), 217-222.

Stein, A., Gath, D., Bucher, J., Bond, A., Day, A., \& Cooper, J. (1991). Multidisciplinary perspectives on postpartum depression: An anthropological critique. Social Science Medicine, 17:1027-1041.

Zimet, G.D., Dahlem, N.W., Zimet, S.G., \& Farley, G.K. (1988). The Multidimensional Scale of Perceived Social Support. Journal of Personality Assessment, 52(1), 30-41. https://doi.orf/10.1207/s15327752jpa5201_2 